Review Paper

\title{
The importance of maximum allowable stem torque in valves
}

\author{
Karan Sotoodeh ${ }^{1}$ \\ (c) Springer Nature Switzerland AG 2019
}

\begin{abstract}
Maximum allowable stem torque/thrust (MAST) is defined as the maximum torque/thrust that can be applied to the valve train without risk of damage, as defined by the valve manufacturer/supplier. The valve train consists of all parts of the valve drive between the operator and closure member, including the closure member but excluding the valve operator such as the gearbox. The important point is that the actuator maximum output torque/thrust based on the maximum supply voltage or operating pressure generated by the actuator should not exceed the valve MAST at any point of travel. The actuator is a component or machine installed on the valve that is responsible for moving (e.g., opening or closing) the valve. This paper provides a formula for calculation of MAST in different sections of a valve stem installed on an oil export pipeline. The result of this calculation shows that the MAST in rectangular section of stem is less than the actuator torque. Two solutions are proposed in this paper; one is to increase the rectangular section diameter, and the second is to upgrade the material to a higher strength option such as Inconel 718. The second solution, which is more expensive, improves the MAST of the stem in all four sections of the circular section with stem keys, stem keys, the circular section, and the rectangular section.
\end{abstract}

Keywords Maximum allowable stem torque (MAST) - Valve design $\cdot$ Actuation $\cdot$ Stem material $\cdot$ Stem diameter $\cdot$ Oil and gas - Offshore

\section{Introduction to MAST}

Maximum allowable stem torque/thrust (MAST) is defined as the maximum torque/thrust that can be applied to a valve train without risk of damage, as defined by the valve manufacturer/supplier [1, 2]. The torque that is applied on the valve train comes from the valve operator, which can be either manual (e.g., a hand wheel plus a gear box operator) or actuated. An actuator is a component or machine installed on the valve that is responsible for moving (e.g., opening or closing) the valve. The drive train includes all parts of the valve drive between the operator and the closure member, including the closure member but excluding the valve operator [1-4]. The drive train in a ball valve includes a solid round stem, a stem key, and a ball, as well as a ball and stem joint [5]. Figure 1 shows ball and stem joint for a large size ball valve. Figure 2 shows a rubber-lined butterfly valve with a stem and its stem key coupling.

It is critical to remember that the actuator maximum output torque/thrust based on the maximum supply voltage or operating pressure, should not exceed the valve MAST at any point of travel [1, 2]. When it comes to manual valves, the torque generated by the gear box is not generally high enough to exceed the MAST. The other reason for having high torque values for actuators is having a safety factor (e.g., 2), calculated using Eq. 1, in designing and sizing the actuators.

Safety Factor $=\frac{\text { Actuator Torque Value }}{\text { Valve Torque Value }}$.

Karan Sotoodeh, karan_sqi@yahoo.com | ${ }^{1}$ Piping Engineering, AkerSolutions, Oslo, Norway.

SN Applied Sciences (2019) 1:433 | https://doi.org/10.1007/s42452-019-0445-0

Received: 17 January 2019 / Accepted: 2 April 2019 / Published online: 9 April 2019

SN Applied Sciences

A SPRINGER NATURE journal 


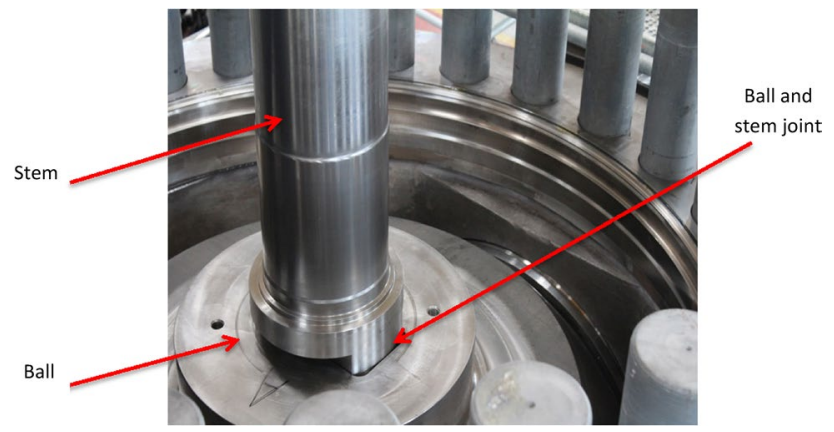

Fig. 1 Ball, Stem and Ball and stem joint for a large size ball valve

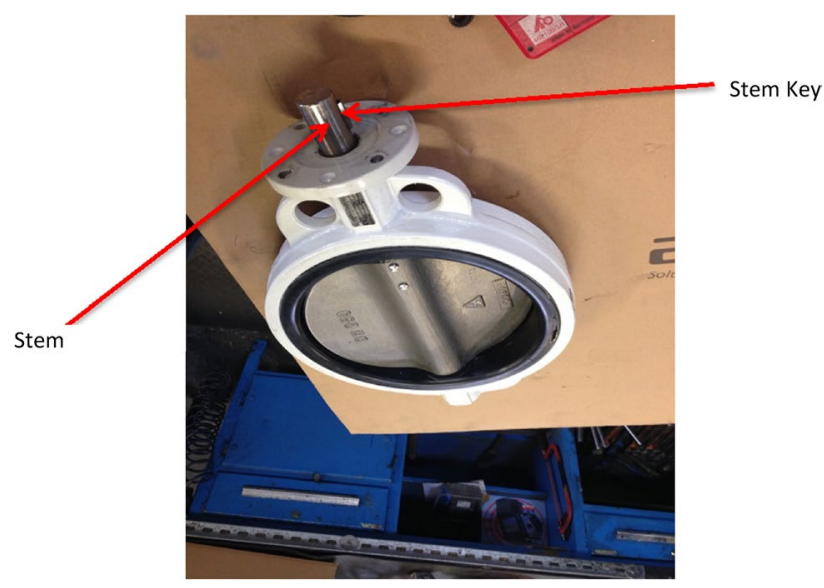

Fig. 2 Stem and stem key for a rubber-lined butterfly valve

\section{MAST limitations}

The maximum allowable stress for different components including the valve stem can be calculated based on ASME code Section VIIII, Div.2, Part AD-132.2, Ed.2004, and ASME code Section II, Part D, Ed. 2017. Equation 2 calculates the maximum allowable stress for valve $S_{m}$ based on material yield strength [6].

$S_{m}=\frac{2}{3} x Y_{S}$

where $S_{m}$ : allowable stress (Ksi); $Y_{S}$ : material yield strength (Ksi).

ASME Code Section VIII, Div.02, Part AD-132.2, provides special stress limit values. The average primary shear stress across a section loaded under design conditions in pure shear (such as keys, shear rings, or screw threads) should be limited to $0.6 S_{m}$. The maximum primary shear under design conditions, exclusive of stress concentration at the periphery of a solid circular section in torsion, should be limited to $0.8 S_{m}[7]$.

Maximum allowable torsional shear

$$
\begin{aligned}
& \text { stress on tem } \leq 0.8 * S_{m}=0.8 \\
& * 2 / 3 * Y_{S}=0.53 * Y_{S}
\end{aligned}
$$

Maximum allowable average primary

$$
\begin{aligned}
& \text { shear stress on stem key } \leq 0.6 * S_{m}=0.6 \\
& * 2 / 3 * Y_{S}=0.4 * Y_{S}
\end{aligned}
$$

Additionally, design stresses for tensile stress, shear stress (including torsional shear stress) and bearing stress should comply with ASME BPVC, Section VIII, except that the design stress intensity value, $S_{m}$, should be taken as $67 \%$ of SMYS $[3,4]$, specified minimum yield strength, as per API 6D and ISO 14313. The shear stress and yield stress units are in N/ $\mathrm{m}^{2}$ or $\mathrm{N} / \mathrm{mm}^{2}$.

\section{MAST calculations}

The stem shown in Fig. 3 contains four sections as follows:

1. Top section contains two keys.

2. Circular part in the middle.

3. Rectangular section at the bottom.

4. Stem keys.

The maximum allowable stem torque for the top section that contains two keys is calculated using Eq. 5 and Roark's equation [5, 8] (Fig. 4).

MAST with 2 keys $=\operatorname{MC} 1=\left(0.53 * Y_{S} * r^{3}\right) / B * 1000$

where MAST is $\mathrm{Nm} ; Y_{S}=$ yield strength $\mathrm{N} / \mathrm{mm}^{2} ; r=$ stem diameter/2 $\mathrm{mm}$.

$B$ is calculated based on Roark's equation (Eq. 6):

$B=K_{1}+K_{2} \frac{b}{r}+K_{3}\left(\frac{b}{r}\right)^{2}+K_{4}\left(\frac{b}{r}\right)^{3}$

where for $0.5 \leq \frac{a}{b} \leq 1$

$K_{1}=1.2512-0.5406 \frac{a}{b}+0.0387\left(\frac{a}{b}\right)^{2}$

$K_{2}=-0.9385+2.3450 \frac{a}{b}+0.3256\left(\frac{a}{b}\right)^{2}$

$K_{3}=7.2650-15.338 \frac{a}{b}+3.1138\left(\frac{a}{b}\right)^{2}$

$K_{4}=-11.152+33.710 \frac{a}{b}-10.007\left(\frac{a}{b}\right)^{2}$ 
Fig. 3 Stem of a valve

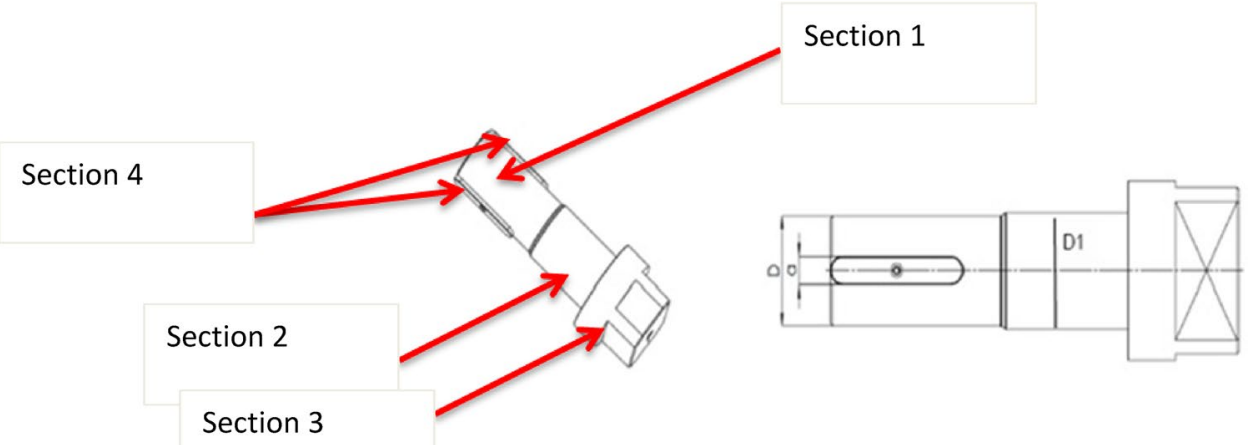

Fig. 4 Shaft with two keys

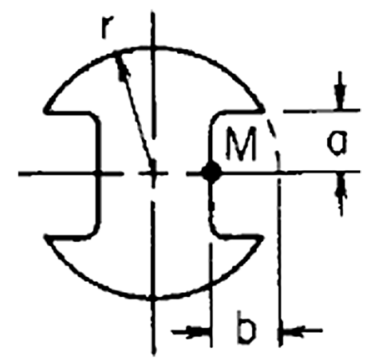

Fig. 5 Solid rectangular section

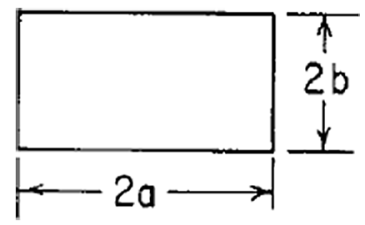

The MAST in the circular section is calculated based on Eq. 7 [5].

MC2 $=\left(0.53 * Y_{S} * 3.14 * D^{3}\right) / 16,000 \mathrm{Nm}$

where $D$ is the stem diameter in the round section.

The MAST in the rectangular section is calculated based on Eq. 8 (Fig. 5) [5, 8].

$\mathrm{MC3}=\left[\left(0.53 * Y_{S}\right) *\left(2 \mathrm{a} * 4 b^{2}\right) /(3+3.6 \mathrm{~b} / \mathrm{B})\right] / 1000 \mathrm{Nm}$

The maximum allowable torque on stem keys has been calculated using Eq. 9 [5, 8] (Fig. 6).

$$
\begin{aligned}
\mathrm{MC4} & =\left[\left(0.6 * S_{m} * \mathrm{D} * \mathrm{~L} * \mathrm{a}\right) / 2000\right] * \mathrm{n} \\
& =\left[\left(0.6 * 0.67 * Y_{S} * \mathrm{D} * \mathrm{~L} * \mathrm{a}\right) / 2000\right] * \mathrm{n} \\
& =\left[\left(0.402 * Y_{S} * \mathrm{D} * \mathrm{~L} * \mathrm{a}\right) / 2000\right] * \mathrm{n}
\end{aligned}
$$

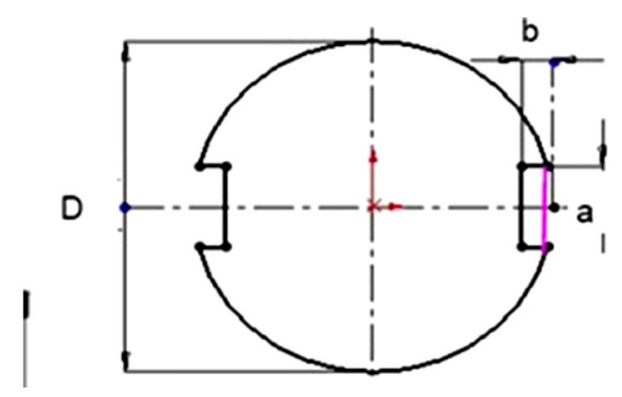

Fig. 6 Stem key section

where a: width of key (mm), L: length of key (mm), n: number of keys, D: stem diameter (mm), b: key groove $(\mathrm{mm})$.

Valve final MAST $=$ Min (MC1, MC2, MC3, MC4).

\section{Case study}

A 30" Class 1500 actuated top entry ball valve is installed on an oil export pipeline. The top entry design which is welded to the pipeline from both sides reduces the leakage possibility from the valve. Additionally, one piece design of the body in top entry design increases the valve resistance against the loads. The body of this valve is made of low temperature carbon steel ASTM A352 LCC material [9]. The valve has emergency shutdown function with a hydraulic actuator for fast operation. The high pressure of supplied oil to the actuator (e.g. 180 Barg) and high torque and big spring in the actuator provides fast opening and closing of the valve respectively (Fig. 7).

The actuator sizing safety factor for emergency shutdown is 2 . The torque values of the valve based on 250 Barg differential pressures are given in Table 1. Double Isolation and Bleed type 2 valve as per API 6D standard contains two different seats, one with Single Piston Effect (SPE) and the other one with Double Piston Effect 


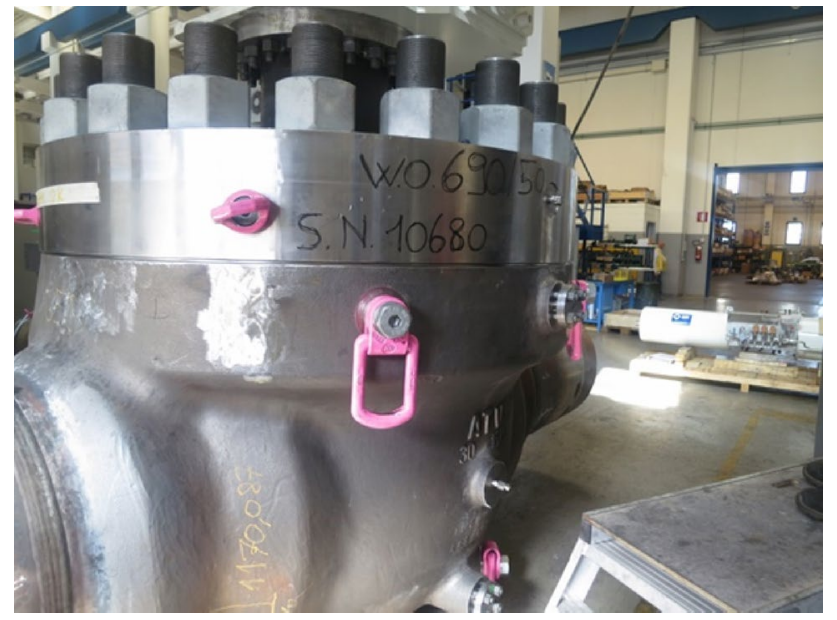

Fig. 7 30"Class 1500 ball valve body

Table 1 Torque values of the 30 " CL1500 top entry ball valve

30 " Class 1500 top entry ball valve, double isolation and bleed type 2, Delta pressure $=250$ Barg

\begin{tabular}{lllllll}
\hline \multicolumn{2}{l}{ Valve to open torque Nm } & & \multicolumn{3}{l}{ Valve to close torque Nm } \\
\cline { 1 - 2 } \cline { 6 - 7 } BTO & Running & ETO & & BTC & Running & ETC \\
\hline 110,016 & 16,215 & 36,852 & & 110,016 & 16,215 & 36,852 \\
\hline
\end{tabular}

(DPE). SPE seat provides isolation from the line side and DPE seat provides double isolations from both the line and valve cavity sides [3].

There are six torque values associated with valves including ball valves [9]:
1. Break to open (BTO) This torque is measured when the valve is closed and the ball opens against just one seat under pressure. This torque, also called breakaway torque which is the largest torque in this case.

2. Running torque (RT) The torque of the valve when the ball opens at approximately $35^{\circ}$ to $45^{\circ}$.

3. End to open (ETO) The torque of the valve when the ball opens at the $80^{\circ}$ position closed to fully open the valve.

4. Break to close (BTC) When the valve is in the fully open position, the torque required to break the open position of the valve to close the valve.

5. End to close (ETC) The torque required to fully close the valve when the valve is about to close.

6. BTO with double block This torque is measured when the valve is closed and the ball opens against both seats under pressure.

Figure 8 shows the position of the ball in different torque conditions.

The maximum valve torque based on Table 1 is $110,016 \mathrm{Nm}$. Considering a safety factor of 2 for actuator sizing and Eq. 1:

Actuator torque $=110,016 \times 2=220,032 \mathrm{Nm}$

Practically, the safety factor of 2 means that the minimum safety factor of 2 is required, so the actuator torque may exceed 220,032 Nm. However, it is assumed in this paper that the safety factor is exactly 2 .

The stem of this valve has been selected in UNS $\$ 41500$, ASTM A182 F6NM. The stem diameter is $300 \mathrm{~mm}$ with two stem keys. The values for other parameters are given below:
Fig. 8 Position of the ball in different torque conditions

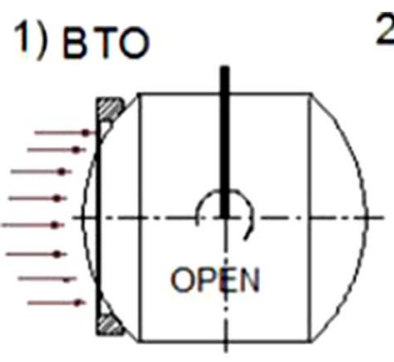

2) $R U N$

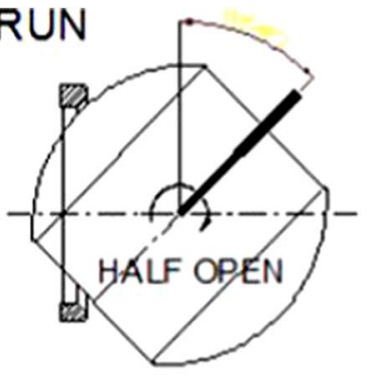

5) ETC

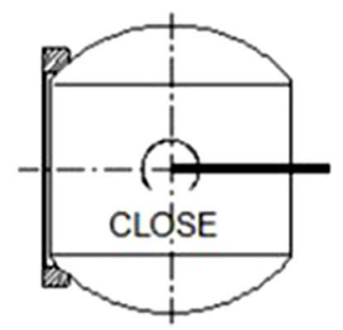

2) ETO

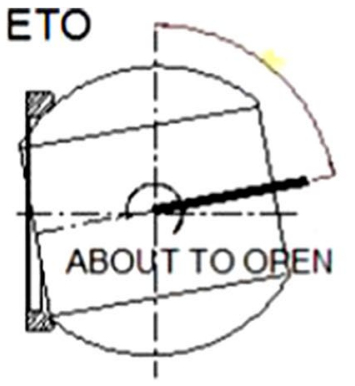

6) BTO WITH DOUBLE
BLOCK

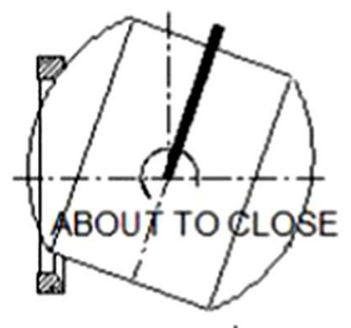

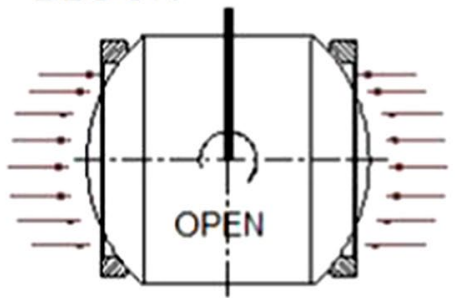

SN Applied Sciences 
$Y_{S}$ for ASTM A182 F6NM $=75 \mathrm{Ksi}=517.10 \mathrm{~N} / \mathrm{mm}^{2}$

$a=100 \mathrm{~mm}, b=100 \mathrm{~mm}, r=150 \mathrm{~mm}, D=300 \mathrm{~mm}$,

$2 a=600 \mathrm{~mm}, 2 \mathrm{~b}=620 \mathrm{~mm}, \mathrm{~L}=150 \mathrm{~mm}, \mathrm{n}=2$.

Using the above parameter values in Eqs. 5, 6, 7, 8 and 9 gives MAST values in different parts of the stem as follows:

$K_{1}=0.7493, K_{2}=1.7321, K_{3}=-4.9592, K_{4}=12.551, B=3.418759$

MAST with 2 keys $=M C 1=270,555.1 \mathrm{Nm}$.

MAST in the circular section $=M C 2=1,452,191.3 \mathrm{Nm}$.

MAST in the rectangular section $=M C 3=191,874.1 \mathrm{Nm}$.

MAST in stem keys $=M C 4=935,433.9 \mathrm{Nm}$.

Note: during the rotation, the contact pressure values between the key grooves and keys as well as rectangular section in contact to ball are important to be checked. Equations 10, 11 and 12 should be used to check the contact pressure between the key and the key grooves.

Contact pressure between key and Grooves $=P=\frac{\text { Force }}{\text { Contact area }}$

Force $=\frac{\text { Torque }}{\text { Stem radious }}$

Contact area $=$ Parameter $\mathrm{a}$ in figure $6 * \mathrm{~L}$ (Length of the key)

\section{Solutions and recommendations}

The MAST in the rectangular section, equal to $191,874.1$, is less than the actuator torque, which is $220,032 \mathrm{Nm}$. The other sections of the stem including stem keys, the rounded part, and the rounded part with keys have a higher torque than the actuator. There are two solutions to increase the stem torque in the rectangular section. The first solution, which is probably the least expensive option, is to increase the area of the rectangular section. Increasing the rectangular area from $600 \mathrm{~mm} \times 620 \mathrm{~mm}$ to $700 \mathrm{~mm} \times 620 \mathrm{~mm}$ increases the MAST in the rectangular area to $223,853.1$, as per Eq. 8. Although this solution is cheaper, it may not be the favourite of valve manufacturers since the stem dimension should be changed to a nonstandard dimension. However, it is possible and practical for a valve manufacturer to increase or reduce the stem dimensions within the tolerance of manufacturing (e.g., plus or minus a $5 \%$ dimension deviation).

The MAST in the rectangular section $=\mathrm{MC} 3$

$$
\begin{aligned}
= & {\left[\left(0.53 * Y_{S}\right) *\left(2 \mathrm{a} * 4 b^{2}\right) /(3+3.6 \mathrm{~b} / \mathrm{B})\right] / 1000 } \\
= & {\left[(0.53 * 517.10) *\left(700 * 620^{2}\right) /\right.} \\
& (3+1.8 * 620 / 3.4187)] / 1000=223,853.1 \mathrm{Nm}
\end{aligned}
$$

The alternative is to change the stem material from ASTM A182 F6NM, 13\% Cr 4\%Ni to Inconel 718. The average yield strength of this material is $130 \mathrm{Ksi}$ equal to $896.3 \mathrm{~N} /$ $\mathrm{mm}^{2}$. Improving the material to Inconel 718 increases the MAST in all four parts of the stem which are rectangular area, rounded part with keys, circular part and stem keys. The MAST value in the rectangular area in Inconel 718 has been increased to $332,579.2 \mathrm{Nm}$, which is more than the actuator torque. Changing the stem material will increase the stem torque values in other parts of stem including the rounded part with keys, the circular part, and stem keys to $468,958 \mathrm{Nm}, 2,517,112 \mathrm{Nm}$, and $1,621,406 \mathrm{Nm}$, respectively. The stem key material is assumed to be the same as the stem material in this paper, which is UNS 541500 , ASTM A182 F6NM before changing the stem material and Inconel 718 in case of upgrading the stem material.

\section{Compliance with ethical standards}

Conflict of interest I declare that there is no conflict of interest.

\section{References}

1. American Petroleum Institute (API) (2012) Standard for actuator sizing and mounting kits for pipeline valves, 1st edn. API, Washington

2. International Organization for Organization (ISO) (2011) Petroleum and natural gas industries: mechanical integrity and sizing of actuators and mounting kits for pipeline valves, 1 st edn. ISO, Geneva

3. American Petroleum Institute (API) (2014) Specification for pipeline and piping valves, 24th edn. API, Washington

4. International Organization for Organization (ISO) (2007) Pipeline transportation systems: pipeline valves, 2 nd edn. ISO, Geneva

5. Piping Engineering (2018) Maximum allowable stem torque. [Online]. Available from: http://www.piping-engineering.com/ maximum-allowable-stem-torque-mast.html. Accessed $10 \mathrm{Sept}$ 2018

6. American Society of Mechanical Engineers (2017) Materials, part D. ASME Boiler and Pressure Vessel Code Section VIII, Division II, ASME, New York

7. American Society of Mechanical Engineers (2004) Rules for construction of pressure vessels, alternative rules. ASME Boiler and Pressure Vessel Code Section VIII, Division II, ASME, New York

8. Young C, Budynas R (2002) Roark's formulas for stress and strain, 7th edn. McGraw-Hill, New York

9. Gokilakrishnan G, Divya S, Rajesh R, Selvakumar V (2014)Operating torque in ball valves: a review. Int J Technol Res Eng 2(4). ISSN: 2347-4718. http://ijtre.com/images/scripts/2014020420 .pdf. Accessed 10 Sept 2018

Publisher's Note Springer Nature remains neutral with regard to jurisdictional claims in published maps and institutional affiliations. 